\title{
Structural and spectroscopic characterization of 1-(diaminomethylene) thiouron-1-ium benzoate and bis(1-(diaminomethylene)thiouron-1-ium) phthalate trihydrate
}

\author{
Genivaldo Julio Perpétuo a , Jan Janczak ${ }^{\text {b, * }}$ \\ ${ }^{a}$ Departamento de Física, Instituto de Ciências Exatas e Biológicas, Universidade Federal de Ouro Preto, 35400-000, Ouro Preto, MG, Brazil \\ ${ }^{\mathrm{b}}$ Institute of Low Temperature and Structure Research, Polish Academy of Sciences, PO Box 1410, 50950, Wroctaw, Poland
}

\section{A R T I C L E I N F O}

\section{Article history:}

Received 9 July 2015

Received in revised form

21 October 2015

Accepted 26 October 2015

Available online 30 October 2015

\section{Keywords:}

1-(diaminomethylene)thiouron-1-ium

benzoate

Bis(1-(diaminomethylene)-thiouron-1-ium)

phthalate trihydrate

Crystal structure

Hydrogen bonds

Vibrational spectroscopy

\begin{abstract}
A B S T R A C T
Two single crystals of 1-(diaminomethylene) thiouron-1-ium benzoate (1) and bis(1-(diaminomethylene)thiouron-1-ium) phthalate trihydrate (2) were grown using a solution growth technique. The compound 1 crystallises in the centrosymmetric $P 2_{1} / c$ space group of the monoclinic system, whereas the compound $\mathbf{2}$ in the centrosymmetric Pbcn space group of orthorhombic system. The solid-state organisation of $\mathbf{1}$ and $\mathbf{2}$ has been analysed with respect to cation-anion and hydrogen bonding interactions. The oppositely charged units interact via almost linear hydrogen bonds with the graphs of $\mathrm{R}_{2}^{2}(8)$ and $\mathrm{R}_{2}^{1}(6)$ forming molecular complexes. In the crystal 1 the $\mathrm{R}_{2}^{2}(8)$ motif is formed by donation to the carboxylate group from amine group joined to $C 1$ and from imine group and $R_{2}^{1}(6)$ motif is formed by donation to the $\mathrm{O} 2$ from amine group joined to $\mathrm{C} 2$ and from imine group, whereas in crystal 2 the graphs are formed oppositely. Interactions between the hydrogen-bonded molecular complexes in $\mathbf{1}$ lead to formation of layered 2D structure, whereas in $\mathbf{2}$, due to presence of hydrated water molecules lead to formation of 3D hydrogen-bonded supramolecular network. The obtained deuterated analogues of $\mathbf{1}$ and $\mathbf{2}$ crystallise similar as H-compound in the monoclinic and orthorhombic system with quite similar lattice parameters. The compounds were also characterised by the FT-IR and Raman spectroscopies. The characteristic bands of the functional and skeletal groups are discussed.
\end{abstract}

() 2015 Elsevier B.V. All rights reserved.

\section{Introduction}

Crystal engineering involving a combination of synthesis and structural chemistry is a branch of material science that rapidly expanding over the past two decades [1,2]. The accurate prediction of a structure and the properties of a product from the structures of basic substrates, which can be considered a designing process, remains the ultimate goal [3]. The exploration of new supramolecular structures and interactions responsible for such an arrangement brings much useful information concerning factors important in structure formation that are helpful in the design process [4]. The hydrogen bonds and other non-covalent intermolecular interactions are of fundamental key for molecular recognition in supramolecular synthesis of new solids [5].

A productive strategy in crystal engineering and control of

\footnotetext{
* Corresponding author.

E-mail address: j.janczak@int.pan.wroc.pl (J. Janczak).
}

crystal architecture is to build supramolecular structures from molecules containing complementary arrays of hydrogen bonding sites [6]. The supramolecular synthon of hydrogen-bonding pattern is an effective approach for structural design of solids [7]. Commercially available 2-imino-4-thiobiuret (Aldrich, CAS No. 2114-20-05) is, as has been shown by the X-ray analysis, it tautomeric form of 1-(diaminomethylene)thiourea (Scheme 1) [8].

Both tautomers are useful in crystal engineering as building blocks, since they contain hydrogen-bonding sites. Additionally, both tautomers can act as $N, N$ - or $N, S$-coordinating ligands forming several types of complexes with metal ions [9]. The 1-(diaminomethylene)-thiourea contains the basic $\mathrm{N}$ atom, therefore it can forms slats with organic and inorganic acids forming extended hydrogen-bonding networks in solids [10]. The supramolecular aggregation pattern of 1-(diaminomethylene)-thiourea with tartaric acid and its deuterated analogue are examples of supramolecular hydrogen-bonding networks in solids that can be utilised as materials for non-linear optics [11].

To explore the usefulness of 1-(diaminomethylene)-thiourea as 
<smiles>CCCC</smiles>

(a)<smiles>CN=C(N)N</smiles>

(b)
Scheme 1. Tautomeric equilibrium between 2-imino-4-thiobiuret (a) and 1-(diaminomethylene)-thiourea (b).

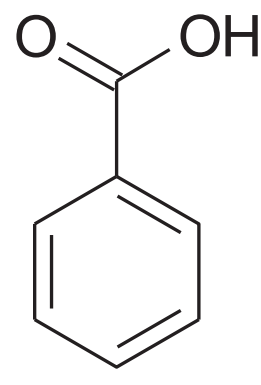

(a)

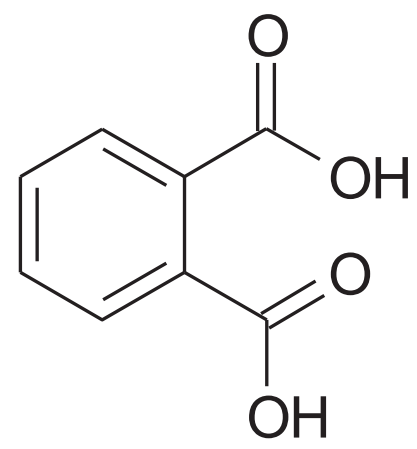

(b)
Scheme 2. Benzoic acid (a) and phthalic acid (b).

a building block in supramolecular synthesis, in the present work we investigate the supramolecular architecture formed by selfassembly of 1-(diaminomethylene)-thiourea with benzoic and phthalic acids (Scheme 2). This study is aimed into the interaction between the building blocks formed the supramolecular architecture in solids. Both compounds were also characterised by vibrational spectroscopy. Assignment of the bands has been supported by the comparison of the IR-spectra of protiated compounds with the IR-spectra of deuterated analogues.

\section{Experimental}

2-imino-4-thiobiuret, benzoic acid and phthalic acid were commercially available and used as received. Elemental analysis was carried out with a Perkin-Elmer 240 elemental analyser.

\subsection{Preparation of 1-(diaminomethylene)thiouron-1-ium benzoate (1) and its deuterated analogue}

Commercially available 2-imino-4-thiobiuret (Aldrich, CAS No. 2114-02-05), which is in fact the tautomeric form 1-(diaminomethylene)thiourea (0.118 g) and the benzoic acid (0.122 g) were added to hot water in a molar proportion of $1: 1$. When the solution became homogeneous it was cooled slowly and kept at room temperature. After several days, transparent colourless crystals of $\mathrm{C}_{6} \mathrm{H}_{5} \mathrm{COO} \cdot \mathrm{C}_{2} \mathrm{H}_{7} \mathrm{~N}_{4} \mathrm{~S}$ (1) were formed. Analysis: calculated for $\mathrm{C}_{8} \mathrm{H}_{12} \mathrm{~N}_{4} \mathrm{SO}_{2}$ : C, 44.98; N, 23.32; O, 13.32; S, 13.34 and $\mathrm{H}, 5.03 \%$. Found: C,45.11; N, 23.22; O, 13.45; S, 13.22, and H, 5.00\%. Deuterated analogue of 1-(diaminomethylene)thiouron-1-ium benzoate was prepared by the usual reaction with heavy water. The crystals of 1(diaminomethylene)thiouron-1-ium benzoate were dissolved in heavy water, and left in the atmosphere saturated with heavy water for one weak, in order to avoid the contamination of the crystals. Next the procedure was repeated twice.

\subsection{Preparation of bis(1-(diaminomethylene)thiouron-1-ium) phthalate trihydrate (2) and its deuterated analogue}

2-imino-4-thiobiuret (0.118 g) and phthalic acid (0.166 g) were dissolved in hot water in a molar proportion of $1: 1$. The solution was cooled and kept at the room temperature. After several days, colourless single crystals of bis(1-(diaminomethylene)thiouron-1ium) phthalate trihydrate (2) were obtained. Analysis: calculated

Table 1

Crystallographic data for 1-(diaminomethylene)thiouron-1-ium benzoate (1) and bis(1-(diaminomethylene)thiouron-1-ium) phthalate trihydrate (2).

\begin{tabular}{|c|c|c|}
\hline & 1 & 2 \\
\hline Empirical formula & $\mathrm{C}_{9} \mathrm{H}_{12} \mathrm{~N}_{4} \mathrm{O}_{2} \mathrm{~S}$ & $\mathrm{C}_{12} \mathrm{H}_{24} \mathrm{~N}_{8} \mathrm{O}_{7} \mathrm{~S}_{2}$ \\
\hline Formula weight $\left(\mathrm{g} \mathrm{mol}^{-1}\right)$ & 240.29 & 456.51 \\
\hline Crystal system & Monoclinic & Orthorhombic \\
\hline Space group & $P 2_{1} / c$ (No. 14 ) & $P b c n($ No. 60$)$ \\
\hline$a(\AA)$ & $17.400(4)$ & $7.9170(16)$ \\
\hline$b(\AA)$ & $4.9390(10)$ & $14.130(3)$ \\
\hline$c(\AA)$ & $13.424(3)$ & $18.293(4)$ \\
\hline$\beta\left({ }^{\circ}\right)$ & $99.13(3)$ & \\
\hline$V\left(\AA^{3}\right)$ & $1139.0(4)$ & $2046.4(7)$ \\
\hline$Z$ & 4 & 4 \\
\hline$D_{\text {calc }} / D_{\text {obs }}\left(\mathrm{g} \mathrm{cm}^{-3}\right)$ & $1.401 / 1.40$ & $1.482 / 1.48$ \\
\hline$\mu\left(\mathrm{mm}^{-1}\right)$ & 0.276 & 0.313 \\
\hline Crystal size (mm) & $0.28 \times 0.14 \times 0.12$ & $0.32 \times 0.24 \times 0.10$ \\
\hline Radiation type, wavelength, $\lambda(\AA)$ & Mo $K \alpha, 0.71073$ & Mo $K \alpha, 0.71073$ \\
\hline Temperature (K) & $295(2)$ & $295(2)$ \\
\hline$\theta$ range $\left(^{\circ}\right)$ & $3.07 \div 29.54$ & $3.09 \div 29.59$ \\
\hline Absorption correction & Numerical, CrysAlis Red & Numerical, CrysAlis Red \\
\hline$T_{\min } / T_{\max }$ & $0.9292 / 0.9651$ & $0.9112 / 0.9708$ \\
\hline Refls collected/unique/observed & $12998 / 2958 / 1546$ & $21484 / 2711 / 1685$ \\
\hline$R_{\text {int }}$ & 0.0572 & 0.0534 \\
\hline Refinement on & $F^{2}$ & $F^{2}$ \\
\hline$R\left[F^{2}>2 \sigma\left(F^{2}\right)\right]$ & 0.0437 & 0.0374 \\
\hline$w R\left(F^{2}\right.$ all reflections $)$ & 0.0627 & 0.0677 \\
\hline Goodness-of-fit, $S$ & 0.989 & 1.001 \\
\hline$\Delta \rho_{\max }, \Delta \rho_{\min }\left(\mathrm{e} \AA^{-3}\right)$ & $+0.162,-0.201$ & $+0.218,-0.189$ \\
\hline
\end{tabular}


for $\mathrm{C}_{12} \mathrm{H}_{24} \mathrm{~N}_{8} \mathrm{O}_{7} \mathrm{~S}_{2}: \mathrm{C}, 31.57 ; \mathrm{N}, 24.55 ; \mathrm{O}, 24.53 ; \mathrm{S}, 14.05$; and $\mathrm{H}$, 5.30\%. Found: C, 31.48; N, 24.60; O, 24.65; S 14.00, and H, 5.27\%. Deuterated analogue of bis(1-(diaminomethylene)thiouron-1-ium) phthalate trihydrate was prepared by the usual reaction with heavy water, and left in the atmosphere saturated with heavy water for one weak, in order to avoid the contamination of the crystals. Next the procedure was repeated twice.

\subsubsection{X-ray data collection}

$\mathrm{X}$-ray intensity data for the $\mathbf{1}$ and $\mathbf{2}$ single crystals were collected using graphite monochromatic Mo K $\alpha$ radiation on a four-circle $\kappa$ geometry KUMA KM-4 diffractometer with a two-dimensional area CCD detector. The $\omega$-scan technique with $\Delta \omega=1.0^{\circ}$ for each image was used for data collection. The 900 images for six different runs covering over $99 \%$ of the Ewald sphere were performed. One image was used as a standard after every 50 images for monitoring of the crystals stability and the data collection. No correction on the

\section{Table 2}

Selected bond lengths $(\AA \AA)$ and angles $\left(^{\circ}\right)$ 1-(diaminomethylene)thiouron-1-ium benzoate (1) and bis(1-(diaminomethylene)thiouron-1-ium) phthalate trihydrate (2).

\begin{tabular}{lll}
\hline & $\mathbf{1}$ & $\mathbf{2}$ \\
\hline $\mathrm{C} 1-\mathrm{S} 1$ & $1.679(2)$ & $1.6640(15)$ \\
$\mathrm{C} 1-\mathrm{N} 1$ & $1.381(3)$ & $1.3837(18)$ \\
$\mathrm{C} 1-\mathrm{N} 2$ & $1.312(3)$ & $1.3216(19)$ \\
$\mathrm{C} 2-\mathrm{N} 1$ & $1.366(3)$ & $1.3609(18)$ \\
$\mathrm{C} 2-\mathrm{N} 3$ & $1.309(3)$ & $1.3214(19)$ \\
$\mathrm{C} 2-\mathrm{N} 4$ & $1.311(3)$ & $1.3008(19)$ \\
$\mathrm{C} 3-\mathrm{O} 1$ & $1.267(2)$ & $1.2706(16)$ \\
$\mathrm{C} 3-\mathrm{O} 2$ & $1.244(2)$ & $1.2492(16)$ \\
$\mathrm{C} 3-\mathrm{C} 4$ & $1.511(3)$ & $1.5025(19)$ \\
$\mathrm{N} 2-\mathrm{C} 1-\mathrm{N} 1$ & $112.7(2)$ & $112.72(13)$ \\
$\mathrm{N} 2-\mathrm{C} 1-\mathrm{S} 1$ & $122.8(2)$ & $121.42(12)$ \\
$\mathrm{N} 1-\mathrm{C} 1-\mathrm{S} 1$ & $124.5(2)$ & $125.86(12)$ \\
$\mathrm{C} 2-\mathrm{N} 1-\mathrm{C} 1$ & $131.4(2)$ & $130.07(13)$ \\
$\mathrm{N} 3-\mathrm{C} 2-\mathrm{N} 4$ & $121.5(2)$ & $120.43(15)$ \\
$\mathrm{N} 3-\mathrm{C} 2-\mathrm{N} 1$ & $115.5(2)$ & $116.51(14)$ \\
$\mathrm{N} 4-\mathrm{C} 2-\mathrm{N} 1$ & $123.1(2)$ & $123.06(14)$ \\
$\mathrm{O} 2-\mathrm{C} 3-\mathrm{O} 1$ & $125.2(2)$ & $124.25(14)$ \\
\hline
\end{tabular}

Table 3

(a) Hydrogen-bond geometry $\left(\AA_{,}^{\circ}\right)$ for 1-(diaminomethylene)thiouron-1-ium benzoate (1) and (b) for bis(1-(diaminomethylene)thiouron-1-ium) phthalate trihydrate (2).

\begin{tabular}{lllll}
\hline$D-H \cdots A$ & $D-\mathrm{H}$ & $\mathrm{H} \cdots A$ & $D \cdots A$ & $D-\mathrm{H} \cdots A$ \\
\hline (a) 1 & & & & \\
$\mathrm{~N} 1-\mathrm{H} 1 \cdots \mathrm{O} 2$ & $0.89(2)$ & $1.89(2)$ & $2.769(2)$ & $165(2)$ \\
$\mathrm{N} 2-\mathrm{H} 21 \cdots \mathrm{O} 1$ & $0.97(2)$ & $1.85(2)$ & $2.806(2)$ & $169(2)$ \\
$\mathrm{N} 2-\mathrm{H} 22 \cdots \mathrm{S} 1^{i}$ & $0.88(2)$ & $2.50(2)$ & $3.368(2)$ & $168(2)$ \\
$\mathrm{N} 3-\mathrm{H} 31 \cdots \mathrm{O} 1^{i i}$ & $0.87(2)$ & $1.98(2)$ & $2.776(3)$ & $152(2)$ \\
$\mathrm{N} 3-\mathrm{H} 32 \cdots \mathrm{O} 2$ & $0.84(2)$ & $2.17(2)$ & $2.896(3)$ & $145(2)$ \\
$\mathrm{N} 4-\mathrm{H} 41 \cdots \mathrm{O} 1^{i i}$ & $0.84(2)$ & $2.16(2)$ & $2.900(3)$ & $148(2)$ \\
$\mathrm{N} 4-\mathrm{H} 42 \cdots \mathrm{S} 1$ & $0.87(2)$ & $2.32(2)$ & $3.025(2)$ & $138(2)$ \\
(b) 2 & & & & \\
$\mathrm{~N} 1-\mathrm{H} 1 \cdots \mathrm{O} 1$ & $0.83(2)$ & $1.94(2)$ & $2.762(2)$ & $170(2)$ \\
$\mathrm{N} 2-\mathrm{H} 12 \cdots \mathrm{O} 1$ & $0.86(2)$ & $2.46(2)$ & $3.190(2)$ & $143(2)$ \\
$\mathrm{N} 2-\mathrm{H} 22 \cdots \mathrm{O} 2^{i}$ & $0.90(2)$ & $2.09(2)$ & $2.966(2)$ & $165(2)$ \\
$\mathrm{N} 3-\mathrm{H} 13 \cdots \mathrm{O} 2$ & $0.89(2)$ & $2.06(2)$ & $2.945(2)$ & $177(2)$ \\
$\mathrm{N} 3-\mathrm{H} 23 \cdots \mathrm{O} 3^{i i}$ & $0.85(2)$ & $2.36(3)$ & $3.078(2)$ & $143(2)$ \\
$\mathrm{N} 3-\mathrm{H} 23 \cdots \mathrm{S} 1^{i i i}$ & $0.85(2)$ & $2.90(3)$ & $3.443(2)$ & $124(2)$ \\
$\mathrm{N} 4-\mathrm{H} 14 \cdots \mathrm{O} 3^{i i}$ & $0.86(2)$ & $2.06(2)$ & $2.880(2)$ & $159(2)$ \\
$\mathrm{N} 4-\mathrm{H} 24 \cdots \mathrm{S} 1$ & $0.86(2)$ & $2.29(2)$ & $3.008(2)$ & $140(2)$ \\
$\mathrm{O} 3-\mathrm{H} 2 \cdots \mathrm{O} 4$ & $0.87(1)$ & $1.94(1)$ & $2.801(2)$ & $170(2)$ \\
$\mathrm{O} 3-\mathrm{H} 3 \cdots \mathrm{O} 2^{i v}$ & $0.86(1)$ & $2.16(1)$ & $3.013(2)$ & $171(2)$ \\
$\mathrm{O} 4-\mathrm{H} 4 \cdots \mathrm{O} 1$ & $0.87(1)$ & $1.86(1)$ & $2.721(2)$ & $171(2)$ \\
\hline
\end{tabular}

Symmetry codes for crystal 1 : (i) $-x+1,-y+2,-z+1$; (ii) $x,-y+3 / 2, z-1 / 2$. Symmetry codes for crystal 2 : (i) $x-1, y, z$; (ii) $-x+1 / 2,-y+1 / 2, z+1 / 2$; (iii) $x+1$, $y, z ;(i v) x-1 / 2, y+1 / 2,-z+1 / 2$. relative intensity variations was necessary. Data collections were made using the CrysAlis CCD program [12]. Integration, scaling of the reflections, correction for Lorentz and polarisation effects and absorption corrections were performed using the CrysAlis Red program [12]. The structures were solved by the direct methods using SHELXS-97 and refined using SHELXL-97 program [13]. The hydrogen atoms involving in the hydrogen bonds were located in difference Fourier maps and were refined. The hydrogen atoms joined to aromatic carbon atoms were introduced in their geometrical positions. The final difference Fourier maps showed no peaks of chemical significance. Details of the data collection parameters, crystallographic data and final agreement parameters are collected in Table 1. Visualisations of the structures were made with the Diamond 3.0 program [14]. Selected geometrical parameters are listed in Table 2 and the geometry of hydrogen bonding interactions is collected in Table 3. The obtained deuterated analogues of $\mathbf{1}$ and $\mathbf{2}$ crystallise similar as H-compounds in the same crystal system with quite similar lattice parameters.

\subsubsection{X-ray powder diffraction}

The protiated and deuterated samples of $\mathbf{1}$ and $\mathbf{2}$ were measured on a PANanalytical X'Pert diffractometer equipped with a $\mathrm{Cu}-\mathrm{K} \alpha$ radiation source $(\lambda=1.54182 \AA)$ at room temperature.

\subsubsection{Vibrational spectra measurements}

The vibrational measurements of $\mathbf{1}$ and $\mathbf{2}$ and theirs deuterated

(a)

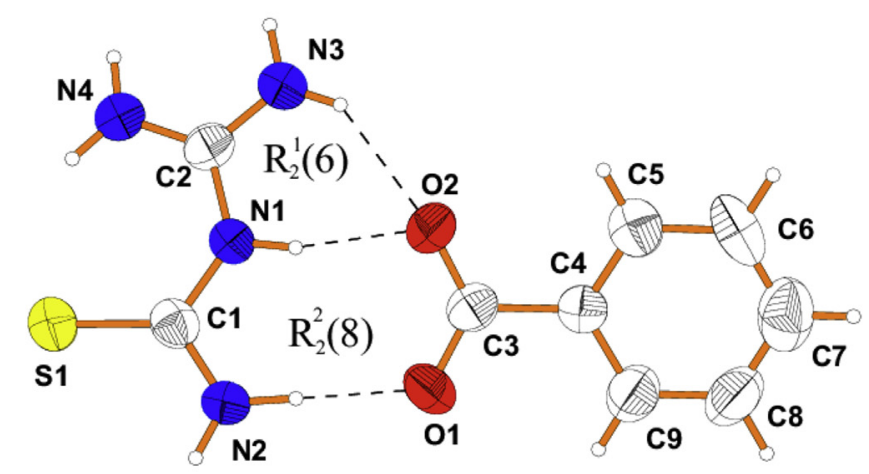

(b)

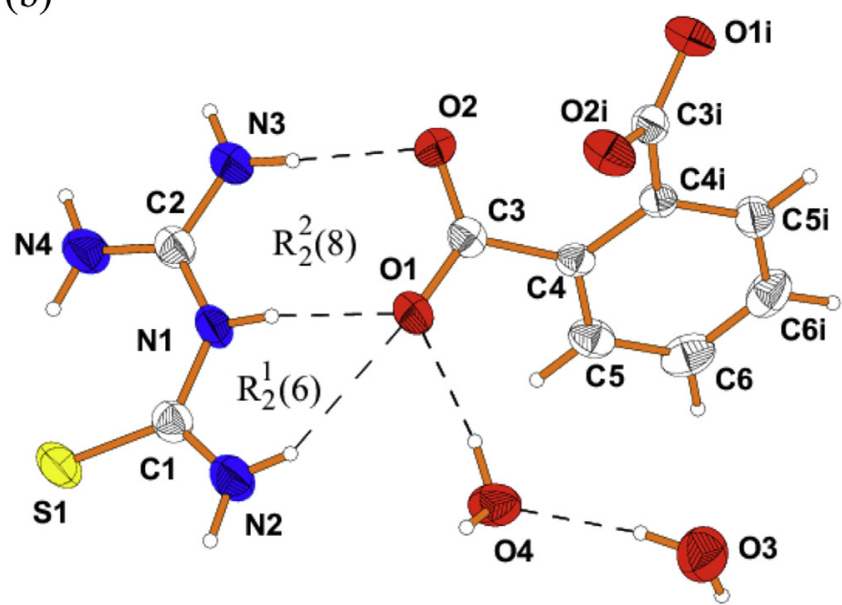

Fig. 1. A view of 1-(diaminomethylene)thiouron-1-ium benzoate (a), bis(1-(diaminomethylene)thiouron-1-ium phthalate trihydrate (b) showing displacement ellipsoids at the $50 \%$ probability level and $\mathrm{H}$ atoms as a sphere of arbitrary radii. Dashed lines represent the hydrogen bonds. Symmetry code: (i) $2-\mathrm{x}, \mathrm{y}, 1.5-\mathrm{z}$. 
analogues were carried out at room temperature. The Fourier transform infrared spectra were recorded from nujol mulls between 4000 and $400 \mathrm{~cm}^{-1}$ on a Bruker IFS 113 V FTIR spectrometer. Resolution was set up to $2 \mathrm{~cm}^{-1}$. The Fourier Transform Raman spectrum was recorded on a FRA-106 attached to the Bruker $113 \mathrm{~V}$ FTIR spectrometer equipped with Ge detector cooled to liquid nitrogen temperature. Resolution was set up to $2 \mathrm{~cm}^{-1}$, signal/noise ratio was established by 32 scans. $\mathrm{Nd}^{3+}$-YAG air-cooled diode pumped laser of power ca. $200 \mathrm{~mW}$ was used as an exciting source. The incident laser excitation was $1064 \mathrm{~nm}$. The scattered light was collected at the angle of $180^{\circ}$ in the region of $3600-80 \mathrm{~cm}^{-1}$, resolution $2 \mathrm{~cm}^{-1}, 256$ scans.

(a)

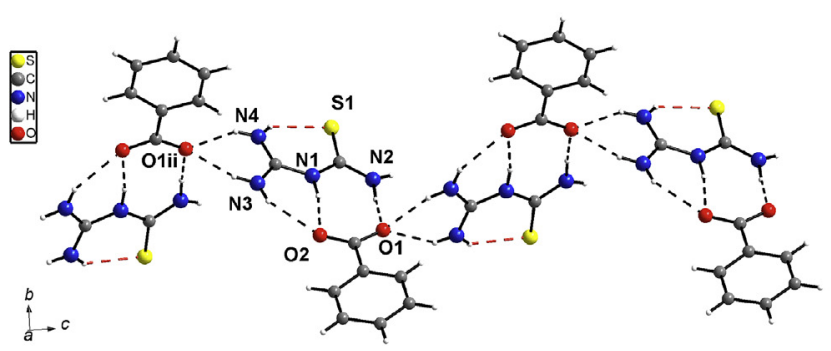

(b)

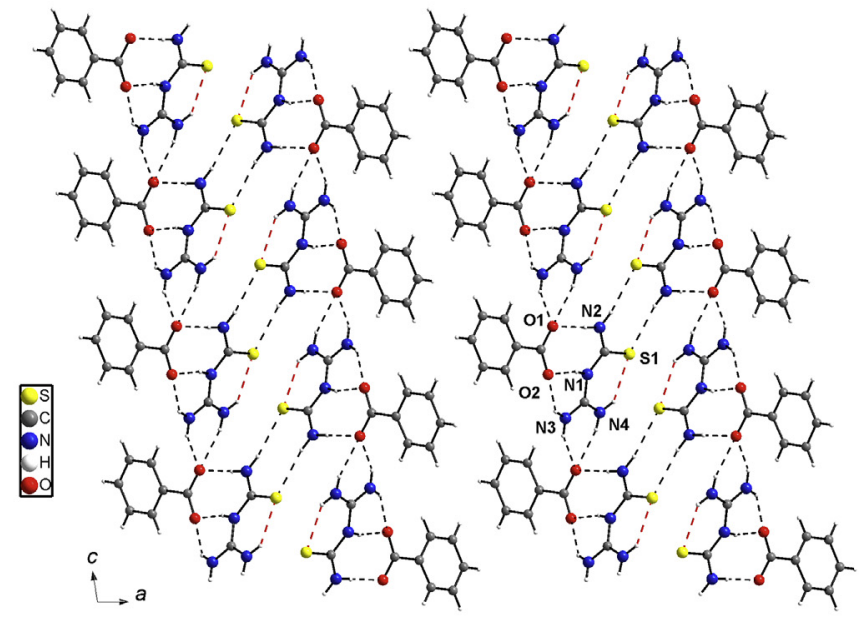

(c)

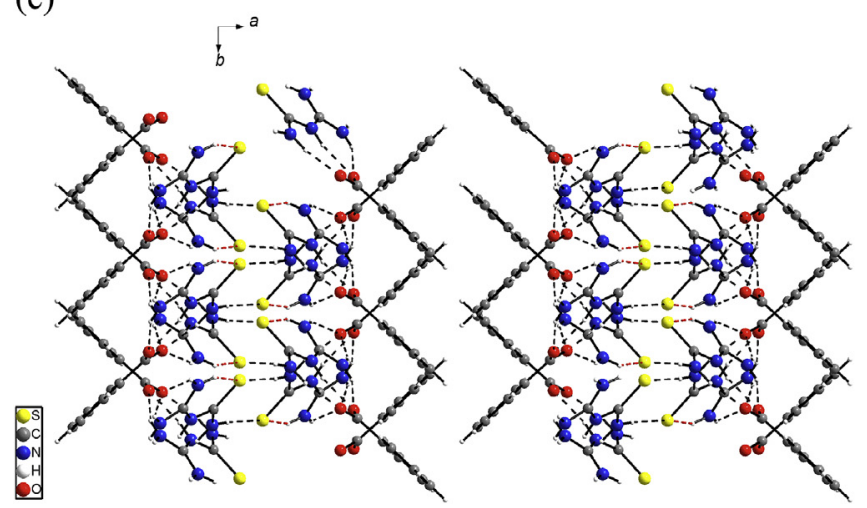

Fig. 2. A view of hydrogen bonded chain of 1-(diaminomethylene)thiouron-1-ium benzoate (a) and the two dimensional hydrogen-bonding layers of 1-(diaminoethylene)hiouron-1-ium benzoate viewed along $b$-axis (b) and $c$-axis (c).

\section{Results and discussion}

Good quality single crystals of 1-(diaminomethylene) thiouron1-ium benzoate (1) and bis(1-(diaminomethylene)thiouron-1-ium) phthalate trihydrate (2) suitable for the X-ray single crystal analysis were obtained from water solutions at ambient temperature. The 1(diaminomethylene) thiouron-1-ium benzoate crystallises in the centrosymmetric space group $P 2_{1} / c$ of monoclinic system whereas bis(1-(diaminomethylene)thiouron-1-ium) phthalate trihydrate crystallises in the centrosymmetric space group $\mathrm{Pbcn}$ of the orthorhombic system. The deuterated analogues were obtained by usual reaction of protiated crystals with heavy water. The deuterated analogues also crystallise as the protiated compounds in the

(a)

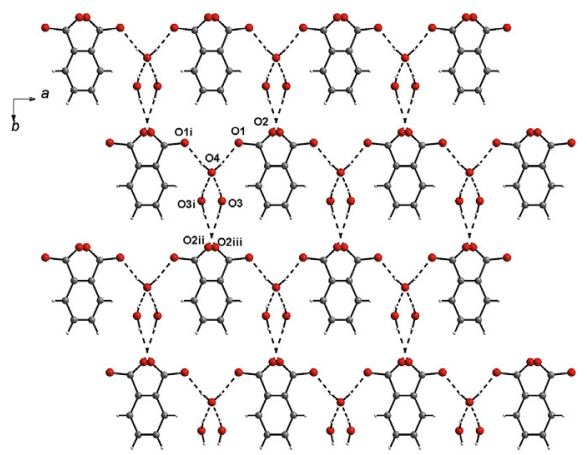

(b)

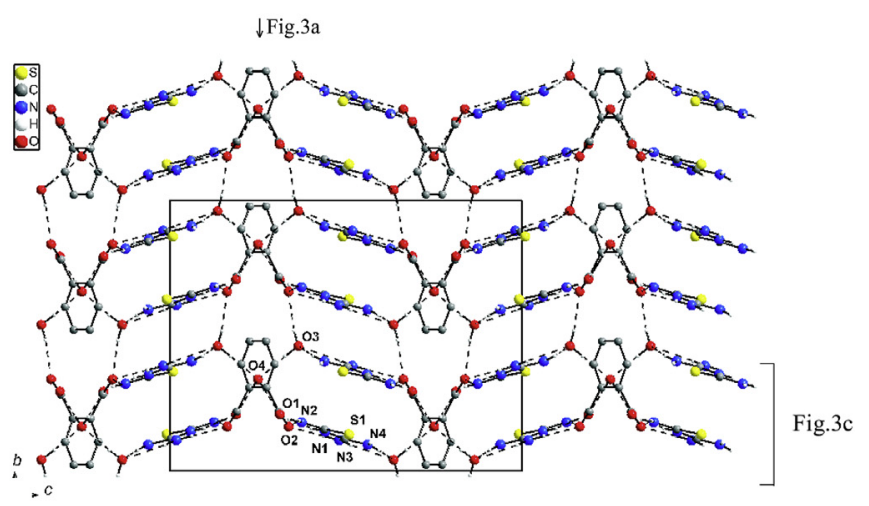

(c)

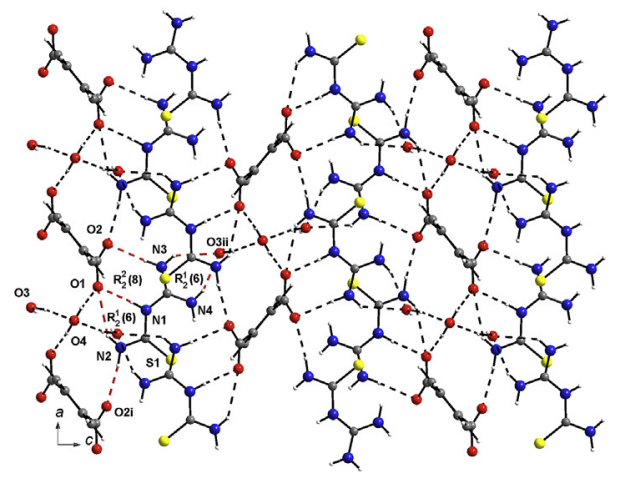

Fig. 3. The anionic 2D-layer of hydrogen bonded by water molecules of phthalate(2-) anions viewed along $c$-axis, symmetry codes $(i)-\mathrm{x}, \mathrm{y}, 0.5-\mathrm{z}$; (ii) $-0.5+\mathrm{x}, 0.5+\mathrm{y}$, $0.5+\mathrm{z}$; (iii) $0.5-\mathrm{x}, 0.5+\mathrm{y}, \mathrm{z}$ (a), 3D hydrogen bonded supramolecular network of bis(1-(diaminomethylene)thiouron-1-ium phthalate trihydrate viewed along $a$-axis (b) and the undulating layer viewed along $b$-axis, symmetry codes: (i) $x-1, y, z$; (ii) $-x+0.5,-y+0.5, z+0.5$ (c). 
same space groups with quite similar lattice parameters, so the protiated and deuterated crystals of $\mathbf{1}$ and $\mathbf{2}$ are isostructural and was confirmed by the powder X-ray diffraction experiments (Figs. S1 and S2 in supplementary material). The microscopic images of $\mathbf{1}$ and $\mathbf{2}$ crystals are shown in Figs. S3 and S4 in supplementary material.

The X-ray single crystal analysis of $\mathbf{1}$ and $\mathbf{2}$ shows that the carboxylate groups are deprotonated, and the proton is transferred to the central $\mathrm{N} 1$ atom of 1-(diaminomethylene) thiourea molecule forming 1-(diaminomethylene) thiouron-1-ium cation. The oppositely charged units interact via almost linear hydrogen bonds with the graphs of $\mathrm{R}_{2}^{2}(8)$ and $\mathrm{R}_{2}^{1}(6)$ forming molecular complexes as illustrate in Fig. 1 . In the crystal 1 the $R_{2}^{2}(8)$ motif is formed by donation to the carboxylate group from amine group joined to $\mathrm{C} 1$ and from imine group and $\mathrm{R}_{2}^{1}(6)$ motif is formed by donation to the $\mathrm{O} 2$ from amine group joined to $\mathrm{C} 2$ and from imine group (Fig. 1a), whereas in crystal 2 the graphs are formed oppositely. In addition, in the hydrated crystals $\mathbf{2}$, hydrogen bonded water dimer interacts with $\mathrm{O} 1$ atom of $\mathrm{COO}^{-}$group via $\mathrm{O}-\mathrm{H} \cdots \mathrm{O}$ hydrogen bond (Fig. $1 \mathrm{~b}$ ).

The conformation of the 1-(diaminomethylene)thiouron-1-ium cation in the crystals $\mathbf{1}$ and $\mathbf{2}$ is not strictly, but twisted. Both arms of the cation are oppositely rotated around the $\mathrm{C}-\mathrm{N}$ bonds involving the central $\mathrm{N} 1$ atom. The dihedral angle between the $\mathrm{N} 1 /$ $\mathrm{C} 1 / \mathrm{S} 1 / \mathrm{N} 2$ and $\mathrm{N} 1 / \mathrm{C} 2 / \mathrm{N} 3 / \mathrm{N} 4$ planes is equal to $3.1(1)^{\circ}$ in crystal 1 and 1.8 (1) in crystal 2 . The dihedral angle in the present structures is significantly smaller than that in the crystal of neutral 1-(diaminomethylene)thiourea $\left(22.2(1)^{\circ}\right)$ [8]. The currently available data on 1-(diaminomethylene)thiouron-1-ium salts [15] show that the cation twisting may differ when different anions are used (1.4 $(1)^{\circ}$ for 1 -(diaminomethylene)thiouron-1-ium perchlorate [10b] to $22.9(1)^{\circ}$ for 1 -(diaminomethylene)thiouron-1-ium chloride [10a]) and is undoubtedly dependent on the hydrogen bonding system formed by the oppositely charged units. The gas-phase conformation of the 1-(diaminomethylene)thiouron-1-ium cation as show the ab-initio MO calculations is also twisted with similar dihedral angle of $6.2^{\circ}$ [10a]. The $\mathrm{C} 1-\mathrm{S} 1$ bond (Table 2 ) is slightly longer than the typical $\mathrm{C}=\mathrm{S}$ double bond as observed in the thioformaldehyde $\mathrm{CH}_{2} \mathrm{C}=\mathrm{S}(1.6019$ (8) $\AA$ ) [16], which represents $100 \%$ double-bond character. The three $\mathrm{C}-\mathrm{N}$ bonds linking the amine groups of the 1-(diaminomethylene)thiouron-1-ium cation in both crystals ( 1 and 2 ) are shorter than the $\mathrm{C}-\mathrm{N}$ bonds involving the central $\mathrm{N} 1$ atom (Table 2). The planarity of the amine groups points to the $s p^{2}$

(a)

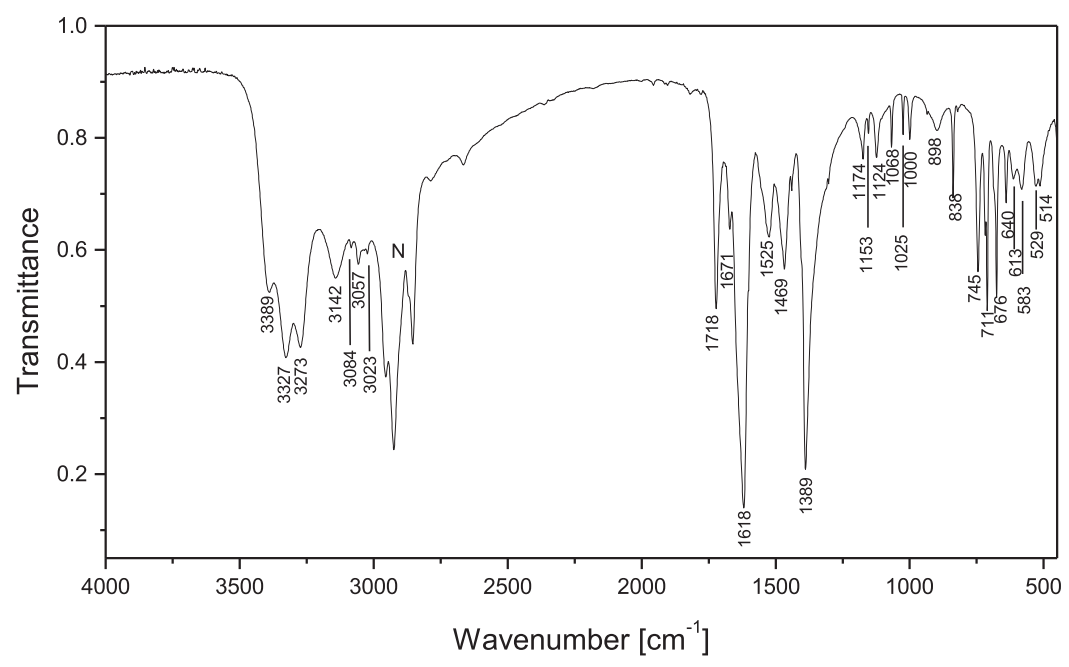

(b)

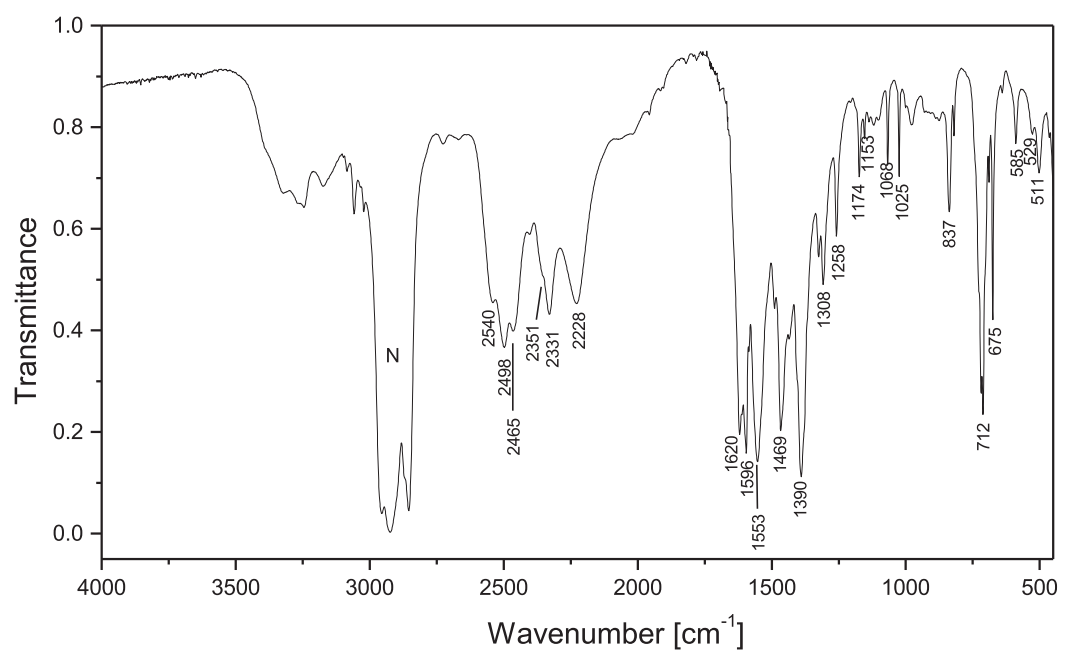

Fig. 4. IR-spectrum of protiated (a) and deuterated analogue (b) of 1-(diaminomethylene)thiouron-1-ium benzoate. 
hybridisation of the orbitals on the amine nitrogen atoms and the lone pair of electron localised on the $p$ orbital. Therefore the partial delocalisation of the lone pair on $p$ orbital of the amine groups and of the $\pi$ bond of the double $\mathrm{C} 1=\mathrm{S} 1$ and $\mathrm{C} 2=\mathrm{N} 1$ bonds is possible and leads to shortening of other $\mathrm{C}-\mathrm{N}$ bonds linking the amine groups and to the elongation of the $\mathrm{C} 1=\mathrm{S} 1$ and $\mathrm{C} 2=\mathrm{N} 1$ bonds (Table 2).

The geometrical parameters of the anionic parts of the crystals, i.e. benzoate(-) and phthalate (2-), do not deviate significantly from the reported values in the other structures containing these anions [15]. The $\mathrm{C}-\mathrm{O}$ bond lengths of the $\mathrm{COO}^{-}$groups (Table 2) point on delocalisation of the $\pi$-bond and the charge over both $\mathrm{C}-\mathrm{O}$ bonds. The $\mathrm{COO}^{-}$group of benzoate $(-)$anion is not coplanar with the benzene ring. It is slightly rotated around the $\mathrm{C} 3-\mathrm{C} 4$ bond. The dihedral angle between the planes of $\mathrm{COO}^{-}$and benzene ring is equal to $10.2(1)^{\circ}$. This is in contrast to the planar conformation of benzoic acid in crystal due to formation of the hydrogen-bonded dimer [17]. The non-planar phthalate (2-) anion has twofold symmetry axis running in the centre of the $\mathrm{C} 4-\mathrm{C} 4^{i}$ and $\mathrm{C} 6-\mathrm{C}^{i}$ bonds (symmetry code as in Fig. 1) with the $\mathrm{COO}^{-}$groups oppositely rotated around the $\mathrm{C} 3-\mathrm{C} 4$ or $\mathrm{C}^{i}-\mathrm{C}^{i}$ by $\pm 48.8(1)^{\circ}$. The rotation angles are greater than that observed in the crystal of pure phthalic acid $\sim 30.5^{\circ}$ [18] due to the repulsive forces between deportonated $\mathrm{COO}^{-}$groups.

In the crystal $\mathbf{1}$, the hydrogen bonding interactions (Table 3a) between the $c$-glide plane related cation-anion molecular complexes lead to formation of chains along the $c$-axis (Fig. 2a). Inversion related chains are arranged parallel to (100) plane forming two dimensional supramolecular layers (Fig. 2b and c). Within the layers the inversion-related chains interact each other via $\mathrm{N}-\mathrm{H} \cdots \mathrm{S}$ hydrogen bonds with a graph of $\mathrm{R}_{2}^{2}(8)$. The importance of such interactions has been questioned [19]. However, the D-H $\cdots S$ interactions $(\mathrm{D}=$ donor) are important in the biological systems due to presence of high content of S atom in biological molecules. In addition, the $\mathrm{N}-\mathrm{H} \cdots \mathrm{S}$ interactions have been utilised for design supramolecular arrangement of thiourea derivatives [20]. Therefore, such $\mathrm{N}-\mathrm{H} \cdots \mathrm{S}$ interactions seem to be important in the present structure (Table 3), where the formation of the intramolecular $\mathrm{N}-\mathrm{H} \cdots \mathrm{S}$ interactions is favoured by the six-membered hydrogenbonded ring with a graph of $S(6)$ and the intermolecular eightmembered hydrogen-bonded ring with a graph of $\mathrm{R}_{2}^{2}(8)$; the presence of $\mathrm{C}=\mathrm{S}$ bonds makes it some resonance-assisted

(a)
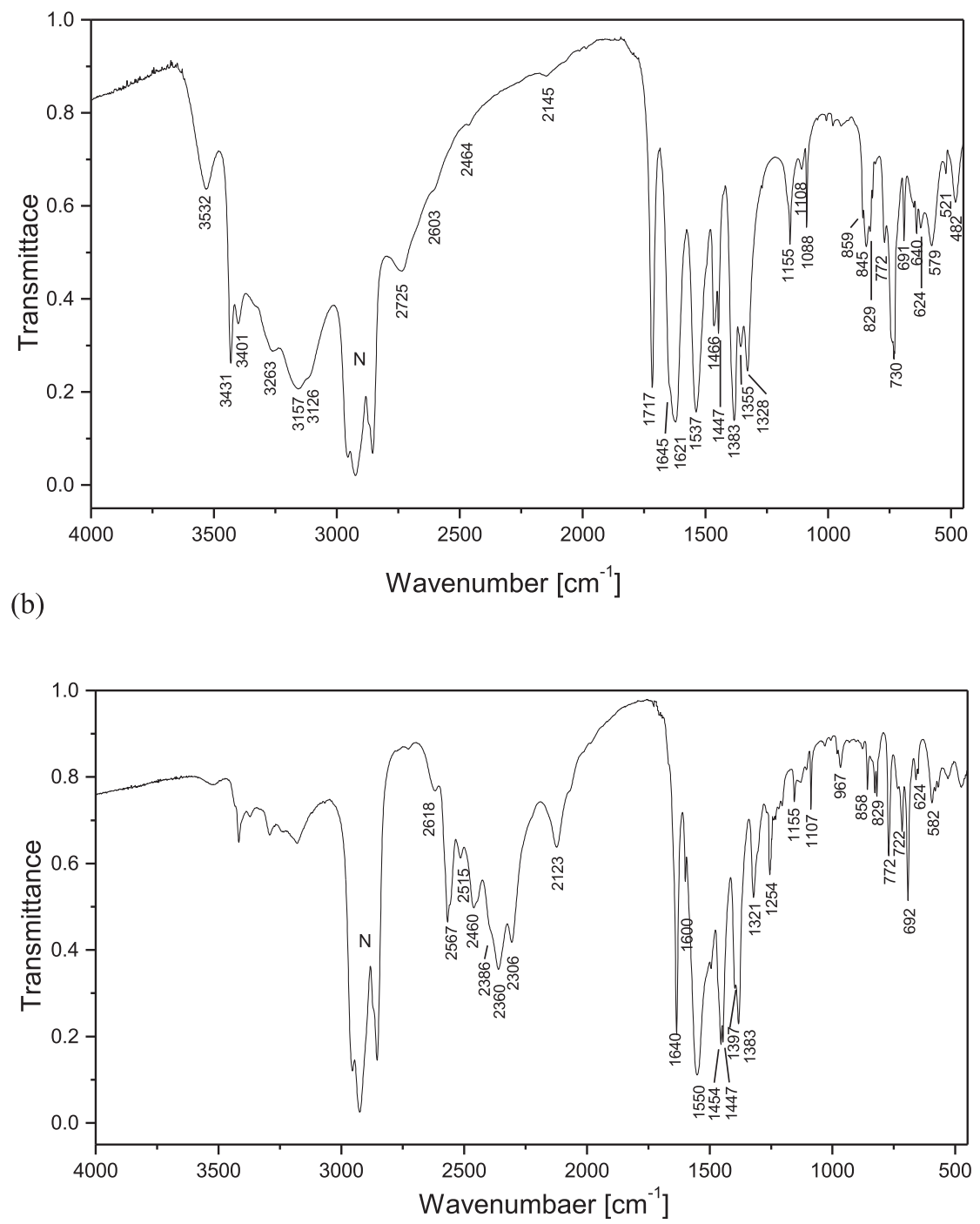

Fig. 5. IR-spectrum of protiated (a) and deuterated analogue (b) of bis(1-(diaminomethylene)thiouron-1-ium phthalate trihydrate. 
stabilisation. The possibility of resonance-induced hydrogen bond ring formation with the $\mathrm{S}$ atom of a $\mathrm{C}=\mathrm{S}$ group with $\mathrm{N}$ substituents has been mentioned by Allen et al. [21]. However, in this structure the hydrogen bonds involving the $\mathrm{S}$ atom seem to be driven by the stronger $\mathrm{N}-\mathrm{H} \cdots \mathrm{O}$ and $\mathrm{O}-\mathrm{H} \cdots \mathrm{O}$ hydrogen bonds (Table 3 ). Neighbouring, $\mathrm{N}-\mathrm{H} \cdots \mathrm{S}$ hydrogen bonded two-dimensional tapes related via translation along the $a$-axis interact mainly via van der Waals forces, since there are no directional interactions between the successive layers (Fig. 2c). There are no $\pi-\pi$ interactions between the aromatic rings of the benzoate anions, since the centre gravity of the rings are separated by 4.939 (4) $\AA$.

In the crystal 2, due to presence of the water molecules, the phthalate(2-) anions are interconnected by water molecules via $\mathrm{O}-\mathrm{H} \cdots \mathrm{O}$ into $2 \mathrm{D}$-layers. Transitionally related along $a$-axis phthalate(2-) anions interact as acceptors with water molecules (O4) forming hydrogen bonded chains aligned along the [100] direction $\left(\mathrm{O} 1 \cdots \mathrm{H}-\mathrm{O} 4-\mathrm{H} \cdots \mathrm{O} 1^{i}\right.$, see Fig. 3a). Neighbouring chains related by $n$-glide plane are combined together by the water molecules (03). The water molecules $\mathrm{O} 3$ are donors in the $\mathrm{O}-\mathrm{H} \cdots \mathrm{O}$ hydrogen bonds, whereas as acceptors play the oxygen atoms (01) of carboxylate groups of one chain and the water molecules (04) of the other chain. The interconnected chains in such manner form anionic $\mathrm{O}-\mathrm{H} \cdots \mathrm{O}$ hydrogen bonding layers parallel to (001) plane (Fig. 3a). Neighbouring, inversion related water-phthalate(2-) anionic layers are located parallel to (001) plane at $z=1 / 4$ and $3 / 4$ (Fig. 3b). The successive $\mathrm{O}-\mathrm{H} \cdots \mathrm{O}$ hydrogen bonding anionic layers are interconnected by 1-(diaminomethylene)thiouron-1-ium cations via $\mathrm{N}-\mathrm{H} \cdots \mathrm{O}$ hydrogen bonds (Table $3 \mathrm{~b}$ ) into threedimensional supramolecular network (Fig. 3b). The 1-(diaminomethylene)thiouron-1-ium cations are alternatively linked via $\mathrm{N}-\mathrm{H} \cdots \mathrm{O}$ hydrogen bonds with $\mathrm{R}_{2}^{2}(8)$ and $\mathrm{R}_{2}^{1}(6)$ graphs to the one anionic layer and with $R_{2}^{1}(6)$ graph to the other anionic layer as illustrated in Fig. 3c forming undulating layer. Repetitive occurrence of $\mathrm{O} 3-\mathrm{H} 3 \cdots \mathrm{O} 2^{i v}$ hydrogen bonds link the undulating layers forming three-dimensional supramolecular network (Fig. 3b). Between the aromatic rings of phthalate anions there are no $\pi-\pi$ interactions, since the center gravity of the rings are separated by 7.917 (3) Å.

The FT-IR spectra of protiated and deuterated analogue of 1(diaminomethylene)thiouron-1-ium benzoate and bis(1-(diaminomethylene)thiouron-1-ium) phthalate trihydrate are shown in Figs. 4 and 5, respectively, whereas the Raman spectra of the

(a)

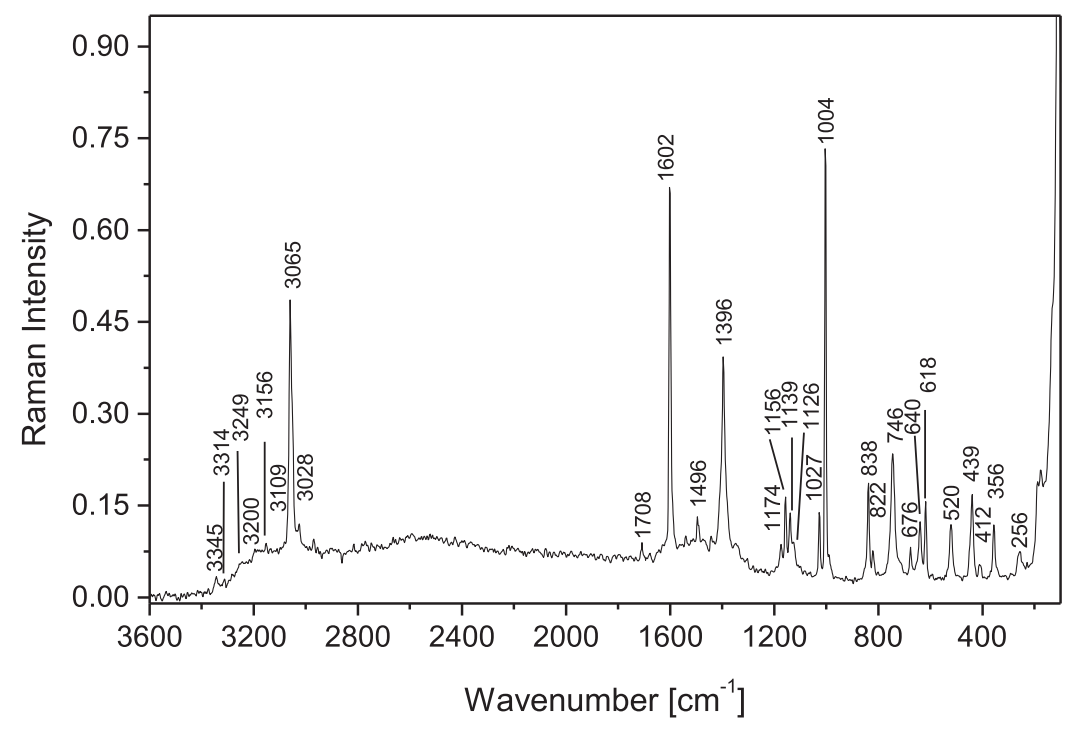

(b)

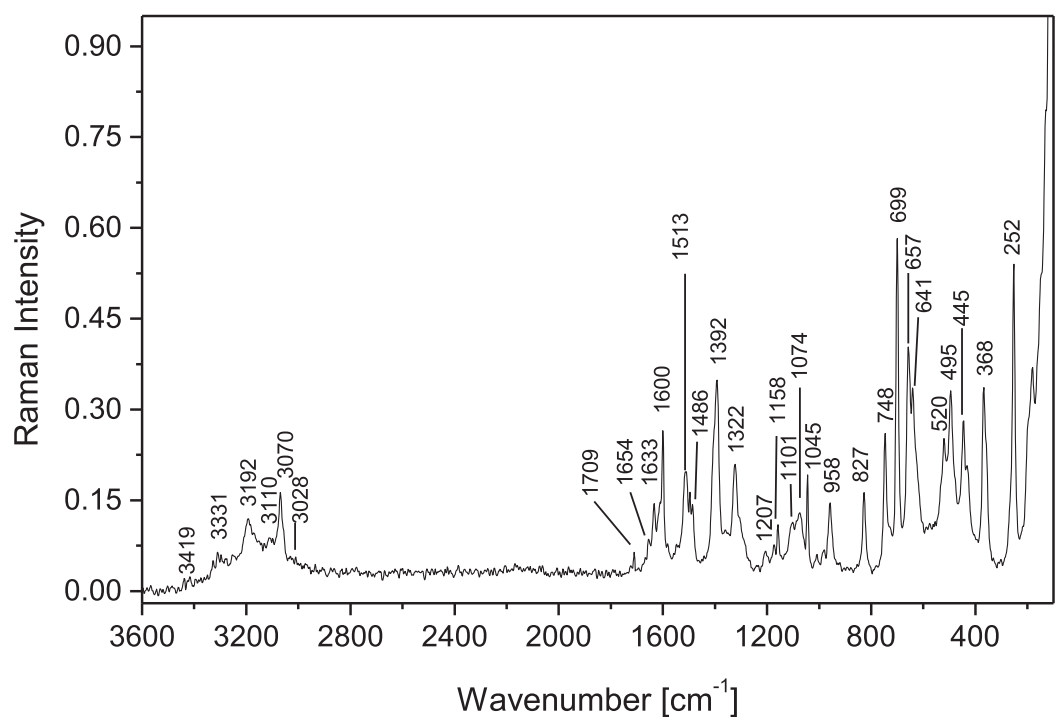

Fig. 6. Raman spectrum of 1-(diaminomethylene)thiouron-1-ium benzoate (a) and bis(1-(diaminomethylene)thiouron-1-ium phthalate trihydrate (b). 
protiated compounds are shown in Fig. 6. The title compounds have several functional and skeletal groups such as three $\mathrm{NH}_{2}, \mathrm{C}=\mathrm{S}$, $\mathrm{C}-\mathrm{N}-\mathrm{C}, \mathrm{N}-\mathrm{C}-\mathrm{N}$ and $\mathrm{N}-\mathrm{C}-\mathrm{S}$ groups in the cation and one or two $\mathrm{COO}^{-}$groups and the six-membered aromatic ring in the anions. The bands corresponding to the vibration of these groups were identified with the aid of infrared correlation charts [22]. The IR spectra of neutral 1-(diaminomethylene)thiourea [10 g] and of benzoic acid [23], phthalic acid [24] as well as benzoate(-) and phthalate(2-) [25] will be helpful for assignment of the bands observed in the spectra of the title compounds (Tables 4 and 5). The IR spectrum of protiated 1-(diaminomethylene)thiouron-1-ium benzoate (Fig. 4a) shows medium-strong intensity bands in the spectral range of 3400 and $3000 \mathrm{~cm}^{-1}$. These bands can be attributed to the asymmetric and symmetric stretching of the three $\mathrm{NH}_{2}$ groups of the 1-(diaminomethylene)thiouron-1-ium cation. These bands, as expected, are shifted in the IR-spectrum of deuterated sample to the spectral region of $2600-2200 \mathrm{~cm}^{-1}$ (Fig. 4b). The isotopic ratio between 1.310 and 1.372 points on the vibration anharmonicity. The IR-spectra of protiated and deuterated samples of bis(1-(diaminomethylene)thiouron-1-ium) phthalate trihydrate show similar correlation between the observed $v_{\text {asym }}\left(\mathrm{NH}_{2}\right)$ and $v_{\text {sym }}\left(\mathrm{NH}_{2}\right)$ and $v_{\text {asym }}\left(\mathrm{ND}_{2}\right)$ and $v_{\text {sym }}\left(\mathrm{ND}_{2}\right)$ (Fig. $5 \mathrm{a}$ and $\left.\mathrm{b}\right)$. The IR spectra of deuterated analogues (Figs. $4 \mathrm{~b}$ and $5 \mathrm{~b}$ ), the bands of the protiated compounds with significantly lower intensities are observed. These bands resulting from the equilibrium between the protiated and deuterated analogues and point on the not fully exchange of $\mathrm{H}$ to $\mathrm{D}$. The degree of deuterization is estimated to $\sim 80 \%$ in 1 and $~ 90 \%$ in 2 . In the Raman spectrum of protiated compounds (Fig. 6) the $v\left(\mathrm{NH}_{2}\right)$ stretching vibration bands appear in the $3350-3000 \mathrm{~cm}^{-1}$ as a very weak once. The Raman spectra exhibit two narrow bands at 3065 and $3028 \mathrm{~cm}^{-1}$ in $\mathbf{1}$ and at 3070 and $3028 \mathrm{~cm}^{-1}$ in 2 and they are assigned to $\mathrm{C}-\mathrm{H}$ stretching of the benzoate and phthalate anions (Table 6). The medium strong intensity band at $1718 \mathrm{~cm}^{-1}$ and $1717 \mathrm{~cm}^{-1}$ in the IR spectrum of benzoate and phthalate salts, respectively, is assigned to the stretching of imine bond of 1-(diaminomethylene)thiouron-1-ium cation, since it is not observed in the IR spectrum of neutral 1(diaminomethylene)thiourea [10 g]. Its counterpart is observed at 1708 and $1709 \mathrm{~cm}^{-1}$ in the Raman spectrum of benzoate and phthalate salts (Fig. 6). A similar band is observed in the IRspectrum of some imines and their salts [26]. This assignment of the imine stretching vibration band is confirmed by IR-spectra of deuterated samples, in which the deuterated imine stretching is observed at $1258 \mathrm{~cm}^{-1}$ in benzoate and at $1254 \mathrm{~cm}^{-1}$ in phthalate (Figs. $4 \mathrm{~b}$ and $5 \mathrm{~b}$, Tables 4 and 5). The isotopic ratio for the band of imine group is equal to 1.366 (for $\mathbf{1}$ ) and 1.369 (for $\mathbf{2}$ ) and points on the almost the same anharmonic vibration. The $v(C=S)$ band of the 1 -(diaminomethylene)thiouron-1-ium cation is observed in the spectral region of $720-710 \mathrm{~cm}^{-1}$ in both salts. The $v(\mathrm{C}=\mathrm{S})$ band in the spectrum of several thiourea metal complexes is observed in the range of $715-700 \mathrm{~cm}^{-1}$ [21]. The 1-(diaminomethylene)thiouron-1-ium cation contains $\mathrm{C}-\mathrm{N}$ and the $\mathrm{C}-\mathrm{N}-\mathrm{C}, \mathrm{N}-\mathrm{C}-\mathrm{N}$ skeletal groups and the respective vibrational bands are also observed (Tables 4 and 5).

The assignment of the IR bands of benzoate(-) and phthalate(2) anions of the samples were made based on the literature [27]. The notation used in the Tables 4 and 5 for benzoate $(-)$ and phthalate(2-) anions for the vibrational modes associated with the benzene ring is commonly used for substituted benzene derivatives and is made by analogy to the notation established for the modes of benzene by Wilson [28]. For benzoate(-) and phthalate(2-) anions the characteristic $v(\mathrm{C}-\mathrm{C})_{\mathrm{ar}}, v_{\mathrm{asym}}\left(\mathrm{COO}^{-}\right)$and $v_{\mathrm{sym}}\left(\mathrm{COO}^{-}\right)$bands are observed in the spectral region of $1620-1380 \mathrm{~cm}^{-1}$, and the $\beta(\mathrm{C}-\mathrm{H})$ and $\gamma(\mathrm{C}-\mathrm{H})$ vibrational bands are observed in the range of

Table 4

FT - IR spectral data for protiated and deuterated analogue of 1-(diaminomethylene)thiouron-1-ium benzoate.

\begin{tabular}{|c|c|c|c|}
\hline Protiated, $v \mathrm{~cm}^{-1}$ & Deuterated, $v \mathrm{~cm}^{-1}$ & Assignment & Isotopic ratio \\
\hline $3389 \mathrm{~m}$ & $2540 s$ & $v_{\text {asym }}\left(\mathrm{NH}_{2}\right) / v_{\text {asym }}\left(\mathrm{ND}_{2}\right)$ asym stretch. & 1.334 \\
\hline $3327 s$ & $2498 s$ & $v_{\text {asym }}\left(\mathrm{NH}_{2}\right) / v_{\text {asym }}\left(\mathrm{ND}_{2}\right)$ asym stretch. & 1.332 \\
\hline $3273 s$ & $2465 s$ & $v_{\text {asym }}\left(\mathrm{NH}_{2}\right) / v_{\text {asym }}\left(\mathrm{ND}_{2}\right)$ asym stretch. & 1.328 \\
\hline $3142 \mathrm{~m}$ & $2351 \mathrm{~m}$ & $v_{\text {sym }}\left(\mathrm{NH}_{2}\right) / v_{\text {sym }}\left(\mathrm{ND}_{2}\right)$ sym stretch & 1.336 \\
\hline $3084 w$ & $2331 \mathrm{~m}$ & $v_{\text {sym }}\left(\mathrm{NH}_{2}\right) / v_{\text {sym }}\left(\mathrm{ND}_{2}\right)$ sym stretch & 1.323 \\
\hline $3057 w$ & $2228 \mathrm{~m}$ & $v_{\text {sym }}\left(\mathrm{NH}_{2}\right) / v_{\text {sym }}\left(\mathrm{ND}_{2}\right)$ sym stretch & 1.372 \\
\hline \multicolumn{4}{|l|}{$3023 w$} \\
\hline \multicolumn{4}{|l|}{ broad } \\
\hline band $\sim 2800$ & $\sim 2200$ & $\mathrm{~N}-\mathrm{H} \cdots \mathrm{O} / \mathrm{N}-\mathrm{D} \cdots \mathrm{O}$ hydrogen bonds & \\
\hline $1718 \mathrm{~m}$ & $1258 \mathrm{~m}$ & Imine bond stretch. & 1.366 \\
\hline \multicolumn{4}{|l|}{$1671 w$} \\
\hline $1618 v s$ & $1620 s, 1596 s$ & 8a, 8b (Benzene $v(C C))^{a}$ & \\
\hline $1525 w$ & $1553 \mathrm{~s}$ & $v_{\text {asym }}\left(\mathrm{COO}^{-}\right)$ & \\
\hline $1469 \mathrm{~m}$ & $1469 s$ & 19a (Benzene $v(\mathrm{CC})$ ) overlapped with $v(\mathrm{CN})$ & \\
\hline \multirow[t]{2}{*}{$1389 v s$} & $1390 s$ & $v_{\mathrm{sym}}\left(\mathrm{COO}^{-}\right)$ & \\
\hline & $1308 \mathrm{~m}$ & 14 (Benzene $v(\mathrm{CC})$ ) & \\
\hline $1174 w$ & $1174 w$ & 9a (Benzene $v(C C)$ ) & \\
\hline 1153w & $1153 w$ & $v(\mathrm{CN})$ & \\
\hline $1124 w$ & $1123 w$ & $v(\mathrm{CN})$ & \\
\hline 1068w & $1068 w$ & 18b (Benzene $\delta(\mathrm{CH})$ ) & \\
\hline $1025 w$ & $1025 \mathrm{w}$ & 18a (Benzene $v(\mathrm{CC})$ ) & \\
\hline $1000 w$ & $998 w$ & & \\
\hline \multicolumn{4}{|l|}{$898 w$} \\
\hline $838 \mathrm{~m}$ & $837 \mathrm{~m}$ & $\beta_{\text {sym }}\left(\mathrm{COO}^{-}\right)$ & \\
\hline \multicolumn{4}{|l|}{$745 \mathrm{~m}$} \\
\hline $711 \mathrm{~m}$ & $712 \mathrm{~s}$ & $v(\mathrm{C}=\mathrm{S})$ & \\
\hline $676 \mathrm{~m}$ & $675 m$ & Skeletal C-N-C, N-C-N & \\
\hline $640 w$ & & $\tau\left(\mathrm{NH}_{2}\right), \omega\left(\mathrm{NH}_{2}\right)$ & \\
\hline $613 w$ & & Skeletal C-N-C, N-C-N & \\
\hline $583 w$ & $585 w$ & Skeletal $\mathrm{C}-\mathrm{N}-\mathrm{C}, \mathrm{N}-\mathrm{C}-\mathrm{N}$ & \\
\hline $529 w$ & $529 w$ & $\beta_{\text {asym }}\left(\mathrm{COO}^{-}\right)$ & \\
\hline $514 w$ & $511 w$ & & \\
\hline
\end{tabular}

vs, very strong; s, strong; m, medium; w, weak.

a Notation for the modes of the benzene ring according to Willson [28]. 
Table 5

FT-IR spectral data for protiated and deuterated analogue of bis(1-(diaminomethylene)thiouron-1-ium) phthalate trihydrate.

\begin{tabular}{|c|c|c|c|}
\hline Protiated, $v \mathrm{~cm}^{-1}$ & Deuterated, $v \mathrm{~cm}^{-1}$ & Assignment & Isotopic ratio \\
\hline $3532 \mathrm{~m}$ & $2618 w$ & $v_{\text {asym }}(\mathrm{OH}) / \mathrm{v}_{\text {asym }}(\mathrm{OD})$ (water) & 1.349 \\
\hline $3431 s$ & $2567 \mathrm{~m}$ & $\begin{array}{l}v_{\text {asym }}\left(\mathrm{NH}_{2}\right) / v_{\text {asym }}\left(\mathrm{ND}_{2}\right) \text { asym stretch., } \\
\text { overlapped with } v_{\text {sym }}(\mathrm{OH}) \text { or } v_{\text {sym }}(\mathrm{OD}) \text { (water) }\end{array}$ & 1.337 \\
\hline $3401 \mathrm{~s}$ & $2515 w$ & $v_{\text {asym }}\left(\mathrm{NH}_{2}\right) / v_{\text {asym }}\left(\mathrm{ND}_{2}\right)$ asym stretch. & 1.352 \\
\hline $3263 s$ & $2460 \mathrm{~m}$ & $v_{\text {asym }}\left(\mathrm{NH}_{2}\right) / v_{\text {asym }}\left(\mathrm{ND}_{2}\right)$ asym stretch. & 1.326 \\
\hline $3157 \mathrm{~s}$ & $2386 s$ & $v_{\text {sym }}\left(\mathrm{NH}_{2}\right) / v_{\text {sym }}\left(\mathrm{ND}_{2}\right)$ sym stretch & 1.323 \\
\hline $3126 s$ & $2360 \mathrm{~m}$ & $v_{\text {sym }}\left(\mathrm{NH}_{2}\right) / v_{\text {sym }}\left(\mathrm{ND}_{2}\right)$ sym stretch & 1.310 \\
\hline $3102 s$ & $2306 \mathrm{~m}$ & $v_{\text {sym }}\left(\mathrm{NH}_{2}\right) / v_{\text {sym }}\left(\mathrm{ND}_{2}\right)$ sym stretch & 1.345 \\
\hline \multicolumn{4}{|c|}{ 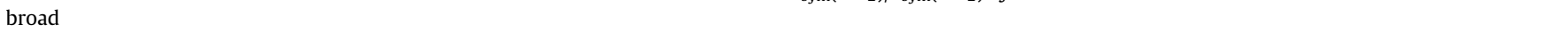 } \\
\hline band & $\sim 2100$ & $\mathrm{~N}-\mathrm{H} \cdots \mathrm{O} / \mathrm{N}-\mathrm{D} \cdots \mathrm{O}$ hydrogen bonds & \\
\hline$\sim 2800$ & $2123 \mathrm{~m}$ & $\mathrm{~N}-\mathrm{H} \cdots \mathrm{O} / \mathrm{N}-\mathrm{D} \cdots \mathrm{O}$ hydrogen bonds & \\
\hline $2725 \mathrm{~m}$ & & $\mathrm{O}-\mathrm{H} \cdots \mathrm{O} / \mathrm{O}-\mathrm{D} \cdots \mathrm{O}$ hydrogen bonds & \\
\hline $2603 w$ & & $\mathrm{O}-\mathrm{H} \cdots \mathrm{O} / \mathrm{O}-\mathrm{D} \cdots \mathrm{O}$ hydrogen bonds & \\
\hline \multicolumn{4}{|l|}{ 2464w } \\
\hline \multicolumn{4}{|l|}{ 2145w } \\
\hline $1717 \mathrm{~s}$ & $1254 \mathrm{~m}$ & Imine bond stretch. & 1.369 \\
\hline $1645 s$ & $1640 s$ & & \\
\hline $1621 v s$ & $1600 \mathrm{~m}$ & 8a, 8b (Benzene $v(C C))^{a}$ & \\
\hline $1537 \mathrm{vs}$ & 1550vs & $v_{\text {asym }}\left(\mathrm{COO}^{-}\right)$ & \\
\hline $1466 \mathrm{~m}$ & $1454 \mathrm{~s}$ & 19a (Benzene $v(\mathrm{CC})$ ) overlapped with $v(\mathrm{CN})$ & \\
\hline \multirow[t]{2}{*}{$1447 \mathrm{~s}$} & $1447 \mathrm{~s}$ & $v(\mathrm{CN})$ & \\
\hline & $1397 \mathrm{~s}$, & & \\
\hline $1383 v s$ & $1383 \mathrm{~s}$ & $v_{\text {sym }}\left(\mathrm{COO}^{-}\right)$ & \\
\hline $1355 \mathrm{~m}$ & $967 w$ & $\delta\left(\mathrm{NH}_{2}\right) / \delta\left(\mathrm{ND}_{2}\right)$ & \\
\hline $1328 \mathrm{~m}$ & $1321 w$ & $v(\mathrm{CN})$ & \\
\hline $1155 \mathrm{~m}$ & 1155w & 9a (Benzene $v(C C)$ ) & \\
\hline $1108 w$ & 1107w & $v(\mathrm{CN})$ & \\
\hline \multicolumn{4}{|l|}{$1088 \mathrm{~m}$} \\
\hline $859 m$ & $858 w$ & & \\
\hline \multicolumn{4}{|l|}{$845 \mathrm{~m}$} \\
\hline $829 m$ & $829 w$ & & \\
\hline $772 \mathrm{~m}$ & $772 \mathrm{~m}$ & $\beta_{\text {asym }}\left(\mathrm{COO}^{-}\right)$ & \\
\hline $730 \mathrm{~m}$ & $722 w$ & $v(\mathrm{C}=\mathrm{S})$ & \\
\hline 691 & $692 \mathrm{~m}$ & 4 (Benzene $v(C C)$ ) & \\
\hline $640 w$ & & $\tau\left(\mathrm{NH}_{2}\right), \omega\left(\mathrm{NH}_{2}\right)$ & \\
\hline $624 w$ & $624 w$ & Skeletal $\mathrm{C}-\mathrm{N}-\mathrm{C}, \mathrm{N}-\mathrm{C}-\mathrm{N}$ & \\
\hline $579 w$ & $582 w$ & Skeletal $\mathrm{C}-\mathrm{N}-\mathrm{C}, \mathrm{N}-\mathrm{C}-\mathrm{N}$ & \\
\hline $521 w$ & $520 w$ & $\beta_{\text {asym }}\left(\mathrm{COO}^{-}\right)$ & \\
\hline $482 w$ & $483 w$ & & \\
\hline
\end{tabular}

vs, very strong; s, strong; m, medium; w, weak.

a Notation for the modes of the benzene ring according to Willson [28].

$1360-1000 \mathrm{~cm}^{-1}$ and $970-740 \mathrm{~cm}^{-1}$, respectively. The assignment of the characteristic $v(\mathrm{C}-\mathrm{C})_{\mathrm{ar}}, v_{\mathrm{asym}}\left(\mathrm{COO}^{-}\right)$and $v_{\mathrm{sym}}\left(\mathrm{COO}^{-}\right)$bands for phthalate(2-) anion has been supported by theoretical calculation performed by Loring et al. [29]. Since the phthalate salt contains hydrated water molecules, in the IR-spectrum the bands of $v_{\text {asym }}(\mathrm{OH})$ and $v_{\text {sym }}(\mathrm{OH})$ are observed as medium bands at 3522 and $3431 \mathrm{~cm}^{-1}$ (Fig. 5a), which are shifted to 2618 and $2567 \mathrm{~cm}^{-1}$ in IRspectrum of the deuterated analogue (Fig. 5b). In the Raman spectrum of hydrated compound 2 the stretching vibration of $\mathrm{O}-\mathrm{H}$ of water are attributed to the weak band at $3419 \mathrm{~cm}^{-1}$ (Fig. 6b). The $\mathrm{X}$-ray data reveal that the $\mathrm{NH}_{2}$ groups of the 1-(diaminomethylene) thiouron-1-ium cation are involved in $\mathrm{N}-\mathrm{H} \cdots \mathrm{O}$ and $\mathrm{N}-\mathrm{H} \cdots \mathrm{S}$ hydrogen bonds. In addition, in the crystal 2 the hydrated water molecules are involved as donors and as acceptors in the $\mathrm{O}_{\text {(water)- }}$ $-\mathrm{H} \cdots \mathrm{O}_{\text {(water) }}$ and $\mathrm{N}-\mathrm{H} \cdots \mathrm{O}_{(\text {water })}$ hydrogen bonds. These hydrogen bonds are relatively weak, with the lengths between the 2.721 (1) and 3.078 (2) $\AA$ (Table 3). This reveals as a broad band in the range of $3300-2500 \mathrm{~cm}^{-1}$ in both protiated samples, which is shifted to $\sim 2200 \mathrm{~cm}^{-1}$ in the deuterated analogues.

\section{Conclusion}

This study confirms the usefulness of 1-(diaminomethylene) thiourea as a building block in the crystal engineering and demonstrates its interaction with benzoic and phthalic acids forming of extended supramolecular hydrogen bonding structures. The $\mathrm{R}_{2}^{2}(8)$ and $R_{2}^{1}(6)$ motifs describe the interaction between the oppositely charged units of the crystals. The hydrogen bonding interactions lead to formation of layered 2D supramolecular structure in 1(diaminomethylene)thiouron-1-ium benzoate (1), whereas in bis(1-(diaminomethylene)-thiouron-1-ium) phthalate trihydrate (2) the hydrogen bonding interactions lead to formation of 3D supramolecular network. In crystal $\mathbf{2}$, the hydrated water molecules are contributed in the formation with phthalate(2-) anions of $\mathrm{O}-\mathrm{H} \cdots \mathrm{O}$ hydrogen bonding anionic 2D layered substructure. In both crystals are no $\pi-\pi$ interactions between the aromatic rings of anions. Comparison of the IR spectra of 1-(diaminomethylene)thiouron-1-ium benzoate and bis(1-(diaminomethylene)-thiouron-1ium) phthalate trihydrate with the spectra of theirs deuterated analogues shows marked differences in the region of vibrations of the amine groups as well as in the region of $\mathrm{N}-\mathrm{H} \cdots \mathrm{O}$ and $\mathrm{O}-\mathrm{H} \cdots \mathrm{O}$ hydrogen bonds.

\section{Supplementary material}

Additional material comprising X-ray powder diffraction patterns of protiated and deuterated samples of 1 and 2 as well as the microscopic images of these two crystals. Full details of the X-ray data collection and final refinement parameters including anisotropic thermal parameters and full list of the bond lengths and angles have been deposited with the Cambridge Crystallographic Data Center in the CIF format as supplementary publications no. 
Table 6

Raman spectral data for 1-(diaminomethylene) thiouron-1-ium benzoate (1) and bis(1-(diaminomethylene)thiouron-1-ium) phthalate trihydrate (2).

\begin{tabular}{|c|c|c|}
\hline $1, v \mathrm{~cm}^{-1}$ & $2, v \mathrm{~cm}^{-1}$ & Assignment \\
\hline & 3419w & $v_{\mathrm{a}}\left(\mathrm{H}_{2} \mathrm{O}\right)$ \\
\hline $3345 w$ & $3331 w$ & $v_{\mathrm{a}}\left(\mathrm{NH}_{2}\right)$ asym stretch. \\
\hline $3314 w$ & & $v_{\mathrm{a}}\left(\mathrm{NH}_{2}\right)$ asym stretch. \\
\hline $3249 w$ & 3240 sh & $v_{\mathrm{a}}\left(\mathrm{NH}_{2}\right)$ asym stretch. \\
\hline $3200 w$ & 3192w & $v_{\mathrm{s}}\left(\mathrm{NH}_{2}\right)$ sym stretch. and $\mathrm{O}-\mathrm{H} \cdots \mathrm{O}$ stretch. \\
\hline 3156w & & $v_{\mathrm{s}}\left(\mathrm{NH}_{2}\right)$ sym stretch. \\
\hline $3109 w$ & 3110w & $v_{\mathrm{s}}\left(\mathrm{NH}_{2}\right)$ sym stretch. \\
\hline $3065 \mathrm{~m}$ & $3070 \mathrm{~m}$ & $\mathrm{C}-\mathrm{H}$ stretch. \\
\hline $3028 w$ & 3028w & $\mathrm{C}-\mathrm{H}$ stretch. \\
\hline \multirow[t]{3}{*}{ 1708w } & $1709 w$ & Imine bond stretch. \\
\hline & $1654 w$ & \\
\hline & $1633 w$ & \\
\hline \multirow[t]{2}{*}{$1602 \mathrm{~m}$} & $1600 \mathrm{~m}$ & $v_{\text {asymm }}\left(\mathrm{COO}^{-}\right), \mathrm{N}-\mathrm{C}-\mathrm{N}$ bend + ring def. \\
\hline & $1513 \mathrm{~m}$ & \\
\hline 1496w & 1486w & $\mathrm{N}-\mathrm{C}-\mathrm{N}$ bend + ring def. \\
\hline \multirow[t]{2}{*}{$1396 m$} & $1392 \mathrm{~m}$ & $v_{\mathrm{sym}}\left(\mathrm{COO}^{-}\right)$ \\
\hline & $1322 \mathrm{~m}$ & $\delta\left(\mathrm{NH}_{2}\right)$ \\
\hline $1174 w$ & $1207 w$ & \\
\hline 1156w & 1158w & $v(\mathrm{C}-\mathrm{N}), v(\mathrm{C}-\mathrm{C})$ \\
\hline \multicolumn{3}{|l|}{$1139 w$} \\
\hline \multirow[t]{2}{*}{$1126 w$} & $1101 w$ & $\Gamma(\mathrm{C}-\mathrm{C})$ \\
\hline & $1074 w$ & \\
\hline $1027 w$ & 1045w & $v(\mathrm{C}-\mathrm{C})$ \\
\hline \multicolumn{3}{|l|}{$1004 \mathrm{~s}$} \\
\hline \multicolumn{3}{|l|}{$838 \mathrm{~m}$} \\
\hline $822 w$ & $827 \mathrm{~m}$ & $\beta_{\text {asym }}\left(\mathrm{COO}^{-}\right)$ \\
\hline \multirow[t]{2}{*}{$746 m$} & $748 \mathrm{~m}$ & $v(\mathrm{C}-\mathrm{C}), v(\mathrm{C}=\mathrm{S})$ \\
\hline & $699 \mathrm{~m}$ & $\mathrm{C}-\mathrm{C}-\mathrm{C}$ def. out of plane of phenol ring \\
\hline $676 w$ & $657 \mathrm{~m}$ & $v(\mathrm{C}-\mathrm{C})$ \\
\hline $640 w$ & $641 \mathrm{~m}$ & $\tau\left(\mathrm{NH}_{2}\right), \omega\left(\mathrm{NH}_{2}\right)$ \\
\hline $618 \mathrm{~m}$ & 610 sh & Skeletal $\mathrm{C}-\mathrm{N}-\mathrm{C}, \mathrm{N}-\mathrm{C}-\mathrm{N}$ \\
\hline \multirow[t]{2}{*}{ 520w } & $520 w$ & $\beta_{\text {asym }}(\mathrm{COO})$ \\
\hline & $495 \mathrm{~m}$ & \\
\hline $439 m$ & $445 \mathrm{~m}$ & \\
\hline $412 w$ & $414 w$ & \\
\hline $356 w$ & $368 \mathrm{~m}$ & Skeletal $\mathrm{C}-\mathrm{N}-\mathrm{C}, \mathrm{N}-\mathrm{C}-\mathrm{N}$, \\
\hline $256 w$ & $252 \mathrm{~m}$ & \\
\hline
\end{tabular}

weak, w; medium, m; strong, s; very, v; shoulder, sh.

CCDC 1409699 and 1409700. Copies of the data can be obtained free of charge on the application to CCDC, 12 Union Road, Cambridge, CB21EZ, UK, (fax: (+44) 1223-336-033; email: deposit@ ccdc.cam.ac.uk).

\section{Appendix A. Supplementary data}

Supplementary data related to this article can be found at http:// dx.doi.org/10.1016/j.molstruc.2015.10.080.

\section{References}

[1] (a) G.R. Desiraju, Crystal Engineering. The Design of Organic Solids, Elsevier, Amsterdam, 1989;

(b) J.C. MacDonald, G.R. Whitesides, Chem. Rev. 94 (1994) 2382-2420;

(c) G.R. Desiraju, Angew. Chem. Int. Ed. 46 (2007) 8342-8352.

[2] (a) J.M. Lehn, Supramolecular Chemistry: Concepts and Perspectives, VCH, Weinheim, 1995;

(b) C.B. Aakeröy, Acta Cryst. B53 (1997) 569-586;

(c) D. Braga, Chem. Commun. (2003) 2751-2754;

(d) G.R. Desiraju, Acc. Chem. Res. 35 (2002) 565-573.

[3] (a) B. Moulton, M.J. Zaworotko, Chem. Rev. 101 (2001) 1629-1658;

(b) G.R. Desiraju, J. Am. Chem. Soc. 135 (2013) 9952-9967.

[4] (a) G.R. Desiraju, Chem. Commun. (1997) 1475-1482;

(b) C.B. Aakeröy, N.R. Champness, C. Janiak, CrystEngComm 12 (2010) 22-43.

[5] (a) G.R. Desiraju, Perespectives in Supramolecular Chemistry, vol. 2, Wiley, Chichester, U.K, 1996;

(b) C.B. Aakeröy, P.D. Chopade, C. Gasner, J. Desper, Chem. Commun. 47 (2011) 4688-4690;

(c) O. Altintas, D. Schulze-Suenninghausen, B. Luy, C. Barner-Kowollik, ACS
Macro. Lett. 2 (2013) 211-216;

(d) C.T. Seto, G.M. Whitesides, J. Am. Chem. Soc. 115 (1993) 905-916;

(e) J.I. Arenas-Garcia, D. Herrera-Ruiz, K. Mondragón-Vásquez, H. MoralesRojas, H. Höpfl, Cryst. Growth Des. 12 (2012) 811-824;

(f) G.R.Desiraju, CrustEngComm 5 (2003) 466-467.

[6] (a) G.M. Whitesides, E.E. Simanek, J.P. Mathias, C.T. Seto, D. Chin, M. Mammen, D.M. Gordon, Acc. Chem. Res. 28 (1995) 37-44;

(b) G.R. Desiraju, Angew. Chem. Int. Ed. 34 (1995) 2311-2327;

(c) T. Steiner, Angew. Chem. Int. Ed. 48 (2002) 49-76;

(d) G.J. Perpetuo, J. Janczak, Acta Cryst. C63 (2007) 0301-0302;

(e) C.C. Seaton, K. Chadwick, G. Sadig, K. Guo, R.J. Davey, Cryst. Growth Des. 10 (2010) 726-733;

(f) B.A. Blight, C.A. Hunter, D.A. Leigh, H. McNab, P.I.T. Thomson, Nat. Chem. 3

(2011) 244-248;

(g) A.J. Wilson, Nat. Chem. 3 (2011) 193-194;

(h) C.C. Cheng, Y.C. Yen, F.C. Chang, RSC Adv. 1 (2011) 1190-1194;

(i) R. Patra, H.M. Titi, I. Goldberg, Cryst. Growth Des. 13 (2013) 1342-1349.

[7] (a) M.C. Etter, J. MacDonald, J. Bernstein, Acta Cryst. B46 (1990) 256-262;

(b) M.C. Etter, Acc. Chem. Res. 23 (1990) 120-126;

(c) M.C. Etter, J. Phys. Chem. 95 (1991) 4601-4610.

[8] J. Janczak, G.J. Perpetuo, Acta Cryst. C64 (2008) o114-0116.

[9] (a) K. Chakrabaty, S.P.S. Gupta, Indian J. Phys. A57 (1983) 205-209;

(b) K. Chakrabaty, T. Kar, S.P.S. Gupta, Acta Cryst. C46 (1990) 2065-2068;

(c) E. Doxiadi, R. Vilar, A.J.P. White, D.J. Williams, Polyhedron 22 (2003) 2991-2998;

(d) M. Hołyńska, M. Korabik, M. Kubiak, Polyhedron 29 (2010) 530-538.

[10] (a) G.J. Perpétuo, J. Janczak, Acta Cryst. C64 (2008) o264-o268;

(b) J. Janczak, G.J. Perpétuo, Acta Cryst. C64 (2008) 0330-0334;

(c) M. Hołyńska, M. Kubiak, Acta Cryst. C64 (2008) o609-0612;

(d) J. Janczak, G.J. Perpétuo, Acta Cryst. C65 (2009) o118-0120;

(e) M. Hołyńska, M. Kubiak, Acta Cryst. C65 (2009) o191-o194;

(f) M. Hołyńska, M. Kubiak, Acta Cryst. C65 (2009) 0410-0413;

(g) J. Janczak, G.J. Perpétuo, J. Mol. Struct. 975 (2010) 166-172;

(h) J. Janczak, G.J. Perpétuo, J. Mol. Struct. 988 (2011) 73-81;

(i) G.J. Perpétuo, J. Janczak, J. Mol. Struct. 1007 (2012) 74-80;

(j) G.J. Perpétuo, J. Janczak, J. Mol. Struct. 10541 (2013) 127-138;

(k) G.J. Perpétuo, R.S. Gonçalves, J. Janczak, J. Mol. Struct. 1096 (2015) 74-83; (1) J. Janczak, Cryst. Growth Des. 15 (2015) 5097-5111.

[11] G.J. Perpétuo, J. Janczak, J. Mol. Struct. 1031 (2013) 14-21.

[12] C.C.D. CrysAlis, CrysAlis Red, Version 171.32.6, Oxford Diffraction Poland, Wrocław, Poland, 2006.

[13] G.M. Sheldrick, SHELXS97, SHELXL97, Programs for Crystal Structures Solution and Refinement, University of Göttingen, Göttingen, Germany, 1997.

[14] K. Brandenburg, H. Putz, DIAMOND Version 3.0, Crystal Impact GbR, Bonn, Germany, 2006.

[15] F.H. Allen, Acta Cryst. B58 (2002) 380-388.

[16] D.R. Johnson, F.X. Powell, W.H. Kirchoff, J. Mol. Spectrosc. 39 (1971) 136-145.

[17] (a) G. Bruno, L. Randaccio, Acta Cryst. B36 (1980) 1711-1712;

(b) D. Feld, M.S. Lahmann, Z. Kristallogr. 157 (1981) 215-231. (c) C.C. Wilson, N. Shankland, A.J. Florence, J. Chem. Soc. Faraday Trans. 92 (1996) 5051-5067; (d) W. Cai, A. Katrusiak, CrystEngComm 14 (2012) 4420-4424.

[18] O. Ermer, Helv. Chim. Acta 64 (1981) 1902-1909.

[19] G.Y. Bai, H.S. Ning, J. Simpson, X.Y. Qin, N. Li, Acta Cryst. E62 (2006) 04567-04568.

[20] F.H. Allen, C.H. Bird, R.S. Rowland, P.R. Raithby, Acta Cryst. B53 (1997) 696-701.

[21] F.H. Allen, C.H. Bird, R.S. Rowland, P.R. Raithby, Acta Cryst. B53 (1997) 680-695.

[22] (a) G. Socrates, Infrared Characteristic Group Frequencies, Wiley-Interscience, Chichester, U.K, 1980;

(b) G. Socrates, Infrared, Raman Characteristic Group Frequencies, third ed., Wiley, New York, USA, 2001.

[23] (a) S. Hayashi, N. Kimura, Bulletin of the Institute for Chemical Research, Kyoto University (1966), 44(4), 335-340. (b) I.D. Reva, S.G. Stepanian, J. Mol. Struct. 349 (1995) 337-340;

(c) S.G. Stepanian, I.D. Reva, E.D. Radchenko, G.G. Sheina, Vibr. Spectrosc. 11 (1996) 123-133.

[24] (a) J.F. Arenas, J.I. Marcos, Spectrochim. Acta A36 (1980) 1075-1081; (b) E.S. Blanca, J.L. Núñez, P. Martinez, J. Mol. Struct. 142 (1986) 45-48.

[25] (a) J.F. Arenas, J.I. Marcos, Spectrochim. Acta A35 (1979) 355-363;

(b) G.B. Deacon, R.K. Phillips, Coord. Chem. Rev. 33 (1980) 227-250;

(c) W. Lewandowski, B. Dasiewicz, P. Koczoń, J. Skierski, K. Dobrosz-Teperek, R. Świsłocka, L. Fuks, W. Priebe, A.P. Mazurek, J. Mol. Struct. 604 (2002) 189-193.

[26] (a) J. Favrot, J.M. Leclercq, R. Roberge, S. Sandorfy, D. Vocelle, Photochem. Photobiol. 29 (1979) 99-108;

(b) J. Favrot, D. Vocelle, C. Sandrofy, Photochem. Photobiol. 30 (1979) 417-421.

[27] G. Varsanyi, Assignments for Vibrational Spectra of 700 Benzene Derivatives, Akademiai Kiado, Budapest, 1972.

[28] E.B. Wilson, Phys. Rev. 45 (1934) 706-714.

[29] J.S. Loring, M. Karlsson, W.R. Fawcett, W.H. Casey, Spectrochim. Acta A57 (2001) 1635-1642. 